and desired relief. A preliminary gastrostomy was performed, and ten days later a low tracheotomy ; then the pharynx was exposed and opened below the hyoid bone and the growth with the larynx, the whole of the lower half of the pharynx, and the left lobe of the thyroid body were removed. The cosophagus, trachea, and the pharynx at the level of the hyoid bone were closed with sutures, and the slin flap replaced. The patient recovered rapidly, and seven weeks after the operation she was comfortable, with weight increased and colour improved. A funnelshaped india-rabber tube lying behind the tongue passing out through the pharyngeal fistula and so downwards to the stomach, allows her to swallow her saliva but not to feed through it. The patient can whisper, although no air from the lungs enters the mouth. The writer states that similar cases have been recorded by Gluck, of Berlin, but none in this country. Andrew Wylie.

Sehlbach (Zella St. Bi.). $-A$ Typical Case of Sudden Cessation of Menses with Angina. "Münch. med. Woch.," March 31, 1908.

The patient, who had a dread of gestation, was greatly alarmed, but the author assured her that the angina was a sufficient cause. This opinion was confirmed by the normal return of menstruation the following month.

Dundas Grant.

Tormene, Enrico (Mantua).--On the Behaviour of the Three Resistences of the Red Blood-Corpuscles in Adenoid Subjects. "Archiv Ital. di Otologia, etc.," November, 1907, p. 501.

This is a preliminary note by way of contribution to the hæmatology and pathogenesis of adenoid regetations. As his observations were made on only six cases the author does not attempt to draw very definite conclusions. He divides the red blood-corpuscles into three groups according to their resistance: maximum, medium, and minimal. He finds that in all his advanced cases there was increase of the maximum resistance. and that this continued for not less than four weeks after the removal of the growths, when it generally sank to normal. The other resistances were too variously affected for any conclusion to be drawn. The author suggests that, as in certain morbid states (e.g. icterus), it substance possessing a catatonic action is found in the blood, there may be in the subjects of adenoid disease a substance with hæmo-anatonic action which will affect certain groups of red corpuscles in an opposite sense to the action of the catatonic agents. In a future work the author hopes to give a definite answer to the interesting questions: Whence do the serums of these adenoids derive their increased potentiality? And whence comes the anatonistic agent that acts on the corpuscles of maximum resistance?

James Done?

\title{
NECK AND THYROID.
}

Jackson, J. M., and Mead, L. G.-Some Clinical Observations on the Diagnosis and Treatment of Exophthalmic Goitre. "Boston Med. and Surg. Journ.," March 12, 1908.

A review of 85 cases ( 80 women and 5 men), treated with neutral hydrobromide of quinine (formula, $\mathrm{C}_{20} \mathrm{H}_{24} \mathrm{~N}_{2} \mathrm{O}_{2} \mathrm{HBr}+\mathrm{H}_{2} \mathrm{O}$ ) in 5 grain capsules three times a day. This drug may have to be given continuously for two years. Thyreoidectin was used in 12 cases. The authors do not 
adrocate sending early cases to the surgeon, as they believe 70 to 80 per cent. are cured by medical treatment.

Macleod Yearsley.

Moty, Dr.-Cervico-cesophayeal Fistu?a. "Gazette des Hopitaux," November, 1907.

In January, 1907, a girl, aged twenty, noticed a swelling at the lower part of her neck. It persisted, and when seen in March a tumefactim the size of a walnut was found partly covered by the sternal head of the right sterno-mastoil ; its position was not changed during deglutition, although this act was attended with some discomfort. A diagnosis of atenitis was made. Iodine was prescribed internally and externally. No improvement ensued, and on May 3 the swelling was opened. A flow of pus followed, giving great relief and rendering deglutition easier. T'en days later the discharge had ceased, but on May 17 the inflammation and pain reappeared. The temperature oscillated between $38^{\circ} \mathrm{C}$. and 40. C. A deep phlegmon of the neck had formed; this was incised, and on passing the finger into the opening made an abscess cavity was discorted occupying the whole of the right lateral part of the neck down to the upper border of the sternum. All symptoms improved under drainage and the prognosis seemed excellent, but seven days later fluid imlibed escaped from the wound; eight days subsequently solids swillowed passed by the same route. Purulent undermining of the cellular planes continued, rendering further incisions necessary. The patient's general condition rapidly became worse. There were extreme pallow, sweating and accelerated respiration; pulse 140 . The apices of the lings were consolidated, probably tuberculous, though examination of the sputum for tubercle bacilli was negative. Death occurred two dars later. As to the pathology of the case the author considers that the lusion was tuberculous, originating as an adenitis, the inflammatory prwess extender to the oesophagus, finally perforating its wall. The prognosis in such cases is exceedingly grave, and early intervention gives the only chance.

H. Clayton Fin.

Guisez, M.-The Value of CEsophagoscopy from a Diagnostic and Therepeutic Point of Vieu. " "La Presse Medicale," February 12, 1908.

Contrary to the usually accepted view that the osophagus is a collapsed tube, the observations of the author with the oesophagoscope on the living subject go to show that it is, for the greater part of its extent, an elongated fusiform cavity. Only for the first $4 \mathrm{~cm}$. of its proximal portion and its terminal $2 \mathrm{~cm}$. are its walls in apposition. This disposition of the tube is ascribed to adhesions binding its wall to aljicint structures and to the aspirating power of the thorax. After passing the osophagoscope for 7 or $8 \mathrm{~cm}$. into the gullet the fusiform portion is reached, and its wall can then be explored without contact with the instrument. Malignant growths or the bulging of an aneurysm (an thus be viewed at a distance, avoiding all chances of perforation as might occur with the ordinary bougie. The appearance of the upper and luwer extremities of the canal presented by this method of examination is fully described; both the author and Killian consider them to be sphineters, closed except during deglutition, etc. As regards diagnosis, the writer is of the opinion that oesophagoscopy is the only method afforing precise evidence concerning lesions of the oesophageal wall or the prosition of a foreinn body. Contrasting the superiority of this methind with others at our disposal, such as the passing of bougies and 
the use of bismuth emulsions with the fluorescent screen, the interesting point is noted that, from the fact that carcinomata are invariably associated with spasmodic strictures usually situated some 4 or 5 cm. abort them, both the bougie and bismuth are in such circumstances arrested on the proximal side of the true lesion. With the osophagoscopte the spasm is easily overcome by the application of cocaine, after which the true nature of the parts berond are revealed. The value of the method in the diagnosis of foreign bodies is discussed. Subjective sensations as an aid to location are often misleading, and the $\mathrm{X}$ rays frequently prove useless either owing to the fact that many bodies do not arrest them or difficulty may be experienced in truly interpreting the projection of the shadow on the screen.

H. Clayton For.

\section{NOSE.}

Dupuy, Homer (New Orleans).-A Preliminary Report on the Putholingir (sic) Relation between the Frontal Sinns and Affections of the Eiye. “New Orleans Med. and Surr. Journ.," December, 1907.

Based on clinical study of 50 selected cases. The author's conclusion is that ocular symptoms, other than orbital alscess, can be due to either acute or chronic suppurations of the sinus. He groups the orular affections thus: Changes in the orbital cavity (orbital abscess), affections of the lids (oedema), conjunctival congestion (invariable in arute. generally absent in chronic, (ases), asthenopia (more than half the (atses), affection of the uveal tract (one case of irido-cyclitis), ptosis (one case), disturbances in vision. Macleod Yearshy.

Albrecht, W. (Berlin).-The Significance of Radiograpthy in the Diagmesis of Accessory Sinus Disease. "Arch. fur Laryngol.," rol. xx, Part II.

In a paper by Goldmann and Killian, baser on the examination of thirty cases, it was shown that on radiographs of the skull taken in the savittal direction, not only were the accessory cavities of the nose cle:rly defined, but a diseased cavity was darkened as compared with a healthy one of the opposite side. The author has investigated the matter not only on patients with sinus disease but also on the cardaver. His results agree in all essentials with those of Goldmann and Killian, and he helieves. as they do, that while radiography is in many cases certainly of no assistance, yet, in the great majority, it leads to conclusions of diagnestic importance.

In empyema of the maxillary antrum the skiagram almost always shows a distinct darkening of the cavity on the affected side as compared with the other. The method is likely, however, to be of comparatively little service in cases of this sort, owing to the greater ease and conrenience of transillumination and exploratory puncture. In growths of the upper jaw radiography is of considerable value in showing the degree to which the growth has invaded the neighbouring parts.

In cases of frontal sinus emprema in which the sinuses are larget and the disease is unilateral, the skiagram shows umistakable darkening of the affected side. It is of very little dia-nostic value in cases of early frontal sinusitis with catarrh and moderate swelling of the mucosa, and also in (ases with small sinuses and when the sharlow is bilateral.

In ethmoid disease the method is of very great value. In no instance. 